\title{
El mestratge d'Antoni M. Badia i Margarit
}

\author{
JOAN VENY I CLAR \\ Universitat de Barcelona \\ Institut d'Estudis Catalans
}

És evident que el professor universitari ha de saber bastir un edifici amb dos aiguavessos: el de la docència i el de la investigació. La meva experiència d'estudiant a la nostra Facultat de Filosofia i Lletres, entre els anys 1949 i 1955, no sempre va ser de constatació, d'acompliment d'aquest savi axioma, car aquell que destacava en la recerca fallava com a transmissor pedagògic, el bon pedagog estava mancat de dimensió investigadora i tampoc mancava, ai!, el qui era privat d'una i altra cosa. Entre les honroses excepcions de la nostra Alma Mater emergia la figura modèlica d'Antoni M. Badia Margarit, admirable com a perfecte posseïdor de les dues vessants.

Quan vaig encetar els cursos d'especialitat (Filologia Romànica), superats els dos anys comuns, que eren com una mena d'ampliació d'un batxillerat de Lletres, em vaig trobar amb un catedràtic en plena joventut, dinàmic i amatent, que feia poc que havia guanyat la càtedra de Gramática Histórica de la Lengua Española, que ja tenia al darrere un bon gruix de publicacions (derivats de IBI i INDE, parlar de Bielsa, resultats de NAVA i MAL en la toponímia, etc.) i que impartia classes amb rigor, claredat $\mathrm{i}$ amenitat, tot atraient vocacions per a la linguística. El terreny àrid, costerut, de la linguística esdevenia en la seva veu una plana fèrtil, una horta feraç a la qual acudíem pol-linitzats per la seva paraula sàvia, motivats per la clara exposició dels temes més abstrusos i endinsant-nos en els que desbrossava o convidava a aprofundir. L'hora de classe se'ns feia curta, no ens n'adonàvem i, com recordava G. Colón, ja el bidell Pascual anunciava amb posat marcial i tibat: "Doctor, la hora". Per si fos poc, cultivava la dimensió humana, organitzant excursions per les terres catalanes que ens familiaritzaven amb la toponímia del país i fomentaven l'amor a la naturalesa i la bona companyonia: tinc records inesborrables del Montnegre, Rasos de Peguera, Montcau, Matagalls (on la sorpresa de la boira ens va fer passar una inoblidable nit de convivència a la muntanya, entre cants, pregàries $i$ acudits al voltant del foc solidari). El batec d'aquesta fibra humana forma part de la seva atractiva personalitat i ha contribuit a la profunda estima que s'ha conquerit al llarg d'una vida plenament dedicada a la universitat. 
El ventall de la producció científica de Badia és ampli i ric. L'amplitud de temes que ha despertat la seva inquietud l'ha fet autoqualificar-se de "tastaolletes". Convindreu amb mi que aquest qualificatiu ha sorgit de la seva modèstia i que és inadequat, car en l'ingent conjunt de la seva obra brilla tant l'ampli treball de síntesi com la monografia aprofundida o la tesi d'interpretació; fins quan tracta un tema sense arribar al fons, resulta fecunda la insinuació de camins a seguir.

Badia, fill de la romanística clàssica, dels Meyer-Lübke, Wartburg, Menéndez Pidal, Spitzer, etc., és diacronista; des que va obrir els ulls a la lingüística s'ha mostrat atret per la dimensió històrica, marc dilatat que també abraça la dialectologia, l'onomàstica, la sociolingüística. És altament simptomàtic que als quinze anys ja escrigués un treball sobre els orígens del català. Evident premonició d'un camí científic jalonat de treballs enriquidors i de satisfaccions acadèmiques.

La porta d'entrada va ser l'aragonès, una llengua de transició entre el castellà i el català, que en la immediata postguerra, quan aquesta llengua era tabú a la universitat (i a molts altres àmbits), tenia per a Badia l'atractiu de les nombroses afinitats amb el català, la seva riquesa dialectal i el seu caràcter d'erm científic, sobre el qual havia caigut la "conspiración del silencio", com deia Amado Alonso. I és així com el jove professor surt a la palestra de la romanística amb un estudi sobre la llengua de Fernàndez de Heredia, al qual en seguirien d'altres sobre morfologia i lèxic aragonès així com una monografia ben reeixida sobre el parlar de Bielsa. Els materials aragonesos recollits sobre el terreny van fer part de la base del seu estudi sobre els derivats de IBI i INDE en la Península Ibèrica, on podem observar com, des dels inicis de la seva labor investigadora, Badia s'imposa la visió romànica dels problemes estudiats: no cal recloure's a l'interior d'una llengua, sinó que cal obrir finestres cap a fora i fer obra comparativa, car el que passa, no passa o passa d'una altra manera extramurs pot fer llum a les nostres interpretacions. Els derivats de IBI i INDE no sols en català sinó en les llengües iberoromàniques va ser el tema de la seva tesi doctoral apadrinada per Dámaso Alonso, que de seguida va apreciar les seves capacitats i entusiasme i va oferir-li collaboració a la prestigiosa editorial Gredos, materialitzada en la Gramática catalana de 1962. "Vd., Badia, siempre tan juncal", li deia amb to afectuós el professor de Linguíistica romànica, el poeta de Hijos de la ira.

La temàtica de la càtedra el va portar a tractar aspectos diversos del castellà: pronunciació, subjuntiu de subordinació, gerundi de posterioritat, imperfet d'indicatiu, omissió del subjecte, etc. Però a les seves classes no mancava l'excurs cap al català: una comparació, un contrast amb aquesta llengua era una sortida cap a un camp quasi interdit que mestres i alumnes sentíem molt proper, molt entranyable.

La preocupació per la lingüîstica històrica va quallar en una voluminosa obra de síntesi que ja cap el 1947 tenia prou avançada. Partint del mètode de Menéndez Pidal i dades de Fouché, Griera i Coromines, teixeix la primera gran 
gramàtica històrica catalana, molt ben estructurada, rica de documentació, amb materials ben organitzats; obra de gran difusió entre els nostres universitaris i ben coneguda entre els estudiosos estrangers. Trenta anys més tard, fou traduida al català, sense l'actualització que hauriem esperat, motivada per les responsabilitats de gestió acadèmica que Badia havia contret en aquelles saons. De llavors ençà han proliferat els treballs puntuals sobre fonètica (precisió sobre el pas de CE a CI, *cerera > cirera), sobre lèxic (el triomf d'alcalde sobre batlle, la història de mots com nafrar, bregar, catarro, pujar, etc.) o sobre la llengua dels nostres escriptors (Llull, Desclot, Jaume I, A. Febrer, Verdaguer, etc.).

Un dels puntals de la lingüística històrica són els dialectes, aquests subsistemes afaiçonats per factors externs (geogràfics, històrics, socials) i interns que constitueixen la llengua històrica. Basta consultar una gramàtica històrica o un diccionari etimològic per a adonar-nos de la seva importància. Badia n'era conscient. Per això, no ha d'estranyar que ja el 1953, al Congrés de Linguística Romànica de Barcelona, llancés, juntament amb Colon, al món científic, el projecte d'un nou atles lingüístic que completés i corregís les deficiències de l'Atlas Lingüístic de Catalunya d'Antoni Griera. Ben aviat, acabada la carrera, vaig ser cridat a unir-me a l'empresa. Badia i jo mateix vam dedicar tot un any a la redacció del qüestionari; fins vaig fruir de l'hospitalitat de la família Badia a Sant Privat per tal d'impulsar el nostre treball. El 1957 vam iniciar les enquestes d'assaig. Badia havia fet les seves primeres armes en l'exploració dialectal dels parlars aragonesos $i$ vaig aprendre molt de la seva experiència $i$ de la seva tècnica d'interrogatori. Malauradament, després d'unes enquestes, les seves ocupacions el van impedir de continuar al front de l'obra $i$ jo en vaig heretar la responsabilitat: no oblidaré mai aquest acte de confiança. Amb un equip competent vam realitzar cent noranta exploracions geolingüístiques a tot el domini i avui, amb la codirecció de Lídia Pons, l'ajut de la Fundació Catalana de Gas i la Unió Europea i dins el marc estimulant de l'Institut d'Estudis Catalans s'ha format una base de dades, s'ha publicat un primer volum d'etnotextos del català oriental i en el curs de dos anys estaran disposats per a la impremta els dos primers volums. Serà un atles que completa i millora l'anterior de Griera, amb una xarxa més àmplia de punts i un quiestionari més extens, amb caràcter etnogràfic ( 2.500 fotografies), pioner a l'estat en la recollida de dades amb magnetòfon. Cal aquí reconèixer el paper medul-lar de Badia com a promotor i impulsor d'un atles que, per les seves característiques, hem de qualificar d'obra nacional.

El gust i l'interès per la dialectologia li devia venir de les arrels de l'avior. Si bé Badia és nascut a Barcelona, els seus antecessors procedien de comarques diverses del Principat, del món rural: Vallmoll, el Pont de l'Armentera (Camp de Tarragona), Castellbisbal (Vallès occidental), Esparreguera (Baix Llobregat). El seu tarannà s'ha mostrat obert a tots els parlars (vegeu el determinant diatòpica de la seva darrera Gramàtica), centrats sobre els eixos sincrònic $\mathrm{i}$ diacrònic: tant s'ha ocupat dels dialectalismes en R. Llull, Emili Vilanova o Maria Antònia Salvà com dels anglicismes del menorquí, la relació entre límits 
comarcals i fronteres dialectals o d'una justificació de la partió català occidental / català oriental vertebrada en la intensitat de la romanització. Tampoc es menyspreable la contribució de Badia a aspectes teòrics com una síntesi de l'evolució dels corrents de la dialectologia o als conceptes de llengua i dialecte.

Lligada estretament a la lingüística històrica es troba l'onomàstica, sigui la toponímia, sigui l'antroponímia, les seves dues branques. Noms de lloc i noms de persona constitueixen sovint etapes fòssils dels episodis de la llengua, graons estàtics superats pel mecanisme canviant del sistema. Badia, habitual excursionista com altres filòlegs (Fabra, Coromines), no sols veu en les muntanyes, comes, barrancs i rierols espais d'assossegador esplaiament sinó que viu aquests llocs adherits als seus noms, amb tota la seva càrrega històrica i semàntica. Com a brillants resultats del seus treballs de camp tenim la identificació de la microtoponímia de les rodalies de Sant Joan de les Abadesses (s. X) relacionada amb els cinc-cents firmants de l'acta de reconeixement de propietat del monestir, la dels noms de lloc de la Roca del Vallès a partir de l'acta de consagració d'aquesta parròquia (s. X) o la de la conquesta de Borriana segons la Crònica de Jaume I. Corprèn, captiva l'ànim pensar que aquests noms hagin pervingut als nostres dies després de set-cents, de nou-cents anys de vida. La inquietud del nostre onomatòleg l'ha empès cap a altres estudis monogràfics com la toponímia de Barcelona i de la Garrotxa, la fitotoponímia, els topònims del camí de Santiago o els derivats de mal 'roca' i nava 'plana alta'. Per si fos poc, la toponímia no ha quedat enrere. Des de 1987 dirigeix la secció catalana d'un programa internaciona PATROM (Patronymica romanica) que té per objectiu la formació d'un gran diccionari dels cognoms de la Romània, antics i moderns, que serà la base d'un altre diccionari dels noms de persona catalans.

La lingüística històrica té també molt a veure amb les variables socials, el contacte de llengües, les actituds interlingüístiques o interdialectals, etc. Badia, agut observador de la realitat social i lingüística de Catalunya, subjecta a profunds canvis arran del col-lapse del 39 amb les ulteriors conseqüències per al futur de la seva llengua i les seves institucions, no podia restar insensible davant la nova situació, els problemes de la qual calia conèixer i descriure. I és per això que, una mica per necessitat, esdevé sociolingüista. Primer, "avant la lettre", quan la sociolingüística encara no tenia nom, ens ofereix dos estudis amb aquesta orientació: el de 1961 posa el dit a la nafra sobre tres problemes del català d'aleshores, avui resolts només parcialment: la immigració, el divorci entre català literari i català col-loquial i la insuficiència dels mitjans de comunicació i d'ensenyament; l'estudi de 1962 ja és un tast sobre el contacte de llenguies català/castellà. Però será pocs anys després (1964-1965) que Badia emprendrà un treball plenament sociolingüístic, La llengua dels barcelonins, per a estudiar les actituds dels ciutadans de Barcelona respecte del català, la influència de la immigració $i$ també per a tractar de sensibilizar els barcelonins respecte a la seva llengua pròpìa. Malgrat alguns aspectes metodològics vulnerables (eren els catalans els més motivats per la quiestió de la llengua i, doncs, els que més responien l'enquesta; l'enquesta era només adreçada als caps de família empadronats a Barcelona; mancava informació sobre el sexe dels 
enquestats) que el mateix Badia ha reconegut amb evident honradesa científica, cal reconèixer el caràcter innovador de l'obra i la seva importància en el naixement de la sociolingüística catalana. La seva activitat en aquest camp encara ha donat fruits sucosos, segons ha assenyalat $\mathrm{F}$. Vallverdú, com la distinció entre bilingüisme natural i ambiental, contacte de llengües, diglòssia, tipologia dels registres, normalització linguística, anivellament lexical, etc. No podem oblidar la seva tesi sobre la ciència connotada aplicada a la linguística catalana segons la qual al nostre domini les grans empreses lingüístiques compten sovint amb la complicitat de la societat catalana: tot $i$ alguna veu discrepant d'aquesta manera de veure i possibles matisacions, hom s'inclina a donar-li la raó quan es pensa en el Diccionari català-valencià-balear o en el I Congrés Internacional de la Llengua Catalana i els compara, per exemple, amb el Vocabolario della Svizzera Italiana, iniciat el 1897 i que encara, cent anys després, es troba a la lletra $C$. En reconeixement a aquesta activitat capdavantera i sòlida, la Direcció General de Política Linguística va instituir un premi amb el seu nom destinat a treballs de sociolingüística.

En el barnillatge multicolor de l'obra de Badia destaquen també els seus treballs de linguística descriptiva. És en aquest camp on van bufar nous aires i la curiositat del mestre no podia mantenir-se al marge dels corrents innovadors. Així, en fonètica experimental, frustrats els seus intents de continuar i renovar el laboratori de Barnils i desitjós de posar-se al dia de les noves tècniques, fa un estatge a Coïmbra amb el professor Lacerda i un altre amb Eugen Dieth a Zurich, ciutat on farà amistat amb il-lustres col-legues; a Estrasburg grava uns films radiològics amb 162 frases curtes que han estat la base d'estudis fonètics posteriors. En fonologia destriarà per commutació els fonemes del català, tot defensant el caràcter fonològic de la vocal neutra pel seu valor opositiu, com també el de les glides $/ \mathrm{j} / \mathrm{i} / \mathrm{w} /$. És ben paradoxal que un investigador que mai $s$ 'ha considerat gramàtic sigui autor de dues gramàtiques importants, ben acollides i difoses: la Gramática catalana de 1951, escrita en castellà per a castellanoparlants, centrada sobretot en la modalitat barcelonina, fidel a la doctrina fabriana, de caire descriptiu i normatiu. Gramàtica perfectament organitzada i de diàfana exposició, que ha gaudit del favor d'un públic ampli. Un encàrrec posterior serà l'origen d'una altra gramàtica (1994), d'orientació diferent: com anuncia el subtítol, és àmpliament descriptiva, de normativa laxa, oberta a la variació dialectal i a la varietat de nivells.

Encara hauria d'afegir - i em deixo altres aspectes- l'edició de textos, com les Regles d'esquivar vocables o mots grossers o pagesívols, publicades el 1950 i que aquests darrers lustres Badia, després d'uns cursos de doctorat, ha treballat amb il-lusió i que, a les portes dels seus gloriosos vuitanta anys, està a punt d'enllestir. Es tracta d'una nova edició millorada, amb comentaris nous sobre els autors i sobre els mots condemnats o beneïts per aquests. Peça fonamental per a la història de la nostra llengua, igual que altres treballs com l'anàlisi crítica de conjunt de les obres de lingüística dels darrers decennis o les semblances de personalitats de la nostra filologia (Galí, Jordi Rubió, Coromines, Sanchis Guarner, Moll). 
També ha maldat per la projecció internacional del català. Això explica el seu important paper en l'organització del VII Congrés Internacional de Lingüística Romànica celebrat a la Universitat de Barcelona (1953), en la fundació de l'Associació Internacional de Llengua i Literatura Catalanes (1968), de la qual fou president, en la impulsió de la Société de Linguistique Romane, que també va presidir, en la direcció de les tasques del departament català del PATROM esmentat o en les conferències i cursets impartits arreu de les universitats europees i americanes.

Pel prestigi assolit, ha estat cridat a formar part de diverses institucions culturals del país, com la Reial Acadèmia de Bones Lletres o l'Institut d'Estudis Catalans, de la Secció Filològica del qual ha estat president i a la que ha infós un gran dinamisme amb l'impuls de l'estàndard oral, les visites anuals a poblacions de l'àrea catalana o l'actualització del Diccionari General.

Per l'amplitud i qualitat del seu treball Badia ha rebut nombrosos premis i reconeixements: premis Antonio de Nebrija, Ciutat de Barcelona, Pompeu Fabra, Premi d'Honor de la Fundació Jaume I, Premi de la Fundació Catalana per a la Recerca, Creu de Sant Jordi, Doctor Honoris Causa per les universitats de Salzburg, Toulouse-le-Mirail, Paris-Sorbonne, Perpinyà, Knox College de Gallesbury (Illinois), Rovira i Virgili, Rector Honorari de la Universitat de Barcelona, President d'Honor del Grup Català de Sociolingüística, etc.

Els col-legues de la Universitat i de l'Institut d'Estudis Catalans celebrarem que, seguint la proverbial tendència dels romanistes a la longevitat, Badia pugui continuar la seva fecunda activitat, a prop de nosaltres, exemple per a nosaltres i per a tots, amb el seu vestit impecable i el somriure a flor de pell; sempre al costat de la seva esposa, estímul constant de la seva brillant trajectòria.

En suma, Badia és un docent modèlic, que ha sembrat vocacions amb el seu mestratge, un investigador que ha obert nous camins de recerca, un ciutadà engatjat amb el seu país, coratjós en les seves decisions i en la defensa dels drets col-lectius, amic del diàleg i la senzillesa, profundament laboriós, pètriament íntegre fins assumir responsabilitats alienes, modest $\mathrm{i}$ autocrític en la valoració dels seus treballs, orgullós dels progressos dels seus deixebles. Una personalitat exemplar, model de ciència i humanitat. 